\title{
Heritabilities of osteochondral lesions and genetic correlations with production and exterior traits in station-tested pigs
}

\author{
H. Luther ${ }^{\dagger}$, D. Schwörer and A. Hofer \\ SUISAG, Allmend, 6204 Sempach, Switzerland
}

(Received 28 November 2006; Accepted 14 June 2007)

\begin{abstract}
Osteochondrosis might reduce the performance of slaughter pigs, longevity of sows and animal welfare. The aim of the present work was to describe the prevalence in Swiss breeds and to analyse the genetic background of osteochondral lesions. Between January 2002 and December 2005, about 9500 station-tested pigs were examined for several exterior traits before slaughtering at the Swiss pig performance testing station using the Swiss linear description system with a scale from 1 to 7 per trait. The animals belonged to three breeds: Large White dam line, Swiss Landrace and Large White sire line. Additionally, a random sample of these pigs $(\mathrm{n}=2622)$ was examined for osteochondral lesions at seven positions of the carcass after dissection. At first, the surface and shape of the femur, humerus, radius and ulna at the joints were evaluated by a trained person. Afterwards these bones were sawed and the state of the cartilage and the distal epiphyseal cartilage of the ulna was examined at the cutting surface. Osteochondral lesions were scored on a scale from 1 to 6 . The prevalence of osteochondral lesions was low at head of humerus, condylus lateralis humeri, radius and ulna proximal and head of femur. Osteochondral lesions at condylus medialis humeri (CMH), distal epiphyseal cartilage of ulna (DEU) and condylus lateralis femoris (CMF) exhibited phenotypic and genetic variance. Their heritabilities ranged from 0.16 to 0.18 using linear mixed animal models. Therefore, it is possible to reduce the prevalence of osteochondral lesions by selection in principle. Exterior traits showed low heritabilities ( 0.10 to 0.26 ) but several favourable genetic correlations with osteochondral lesions at CMH, DEU and CMF with low to moderate magnitude. Genetic correlations between osteochondral lesions and production traits were low.
\end{abstract}

Keywords: genetic correlation, heritability, osteochondritis, pigs

\section{Introduction}

Osteochondrosis $(\mathrm{OC})$ is a disturbance of the enchondral ossification in the joint cartilage and in the growth plates (Olsson and Reiland, 1978). Osteochondral lesions may cause or aggravate leg weakness (Lundeheim, 1987; Jørgensen, 2000), reduce longevity of sows and boars and may be painful, if considerable $\mathrm{OC}$ lesions occur. Therefore, concerning economic and animal welfare aspects, $\mathrm{OC}$ is of noticeable relevance.

It is well known that besides environmental factors genetic effects influence the occurrence of $O C$ lesions (Lundeheim, 1987; Jørgensen and Andersen, 2000; Kadarmideen et al., 2004). The authors estimated low-to-moderate heritabilities for the occurrence of osteochondral lesions and found differences between breeds. But the examination methods, the included cartilages and the prevalence of osteochondral lesions differ between their studies.

\footnotetext{
${ }^{\dagger}$ hlu@suisag.ch
}

Direct selection against osteochondral lesions would be very difficult, because only dissected or X-rayed animals could provide information. Thus, including other genetically related traits - e.g. exterior characteristics - in pig breeding programmes may be a preferable way to control the genetic aspects of $O C$. Therefore, genetic parameters of these related traits, like heritabilities and genetic correlations, are needed. Lundeheim and Rydhmer (1990), Jørgensen and Andersen (2000) and Kadarmideen et al. (2004) estimated genetic correlations between $\mathrm{OC}$ and production traits. They found only few unfavourable associations with moderate magnitude. Some authors (Jørgensen et al., 1995; Jørgensen, 2000) found slight phenotypic associations between $\mathrm{OC}$ and several leg weakness symptoms. But to our knowledge, only Jørgensen and Andersen (2000) estimated genetic correlations between exterior traits and OC. They found some favourable, moderate genetic associations.

The aim of the present study is to describe the prevalence of osteochondral lesions at different positions of the carcass in Swiss breeds based on station-tested pigs, which were 


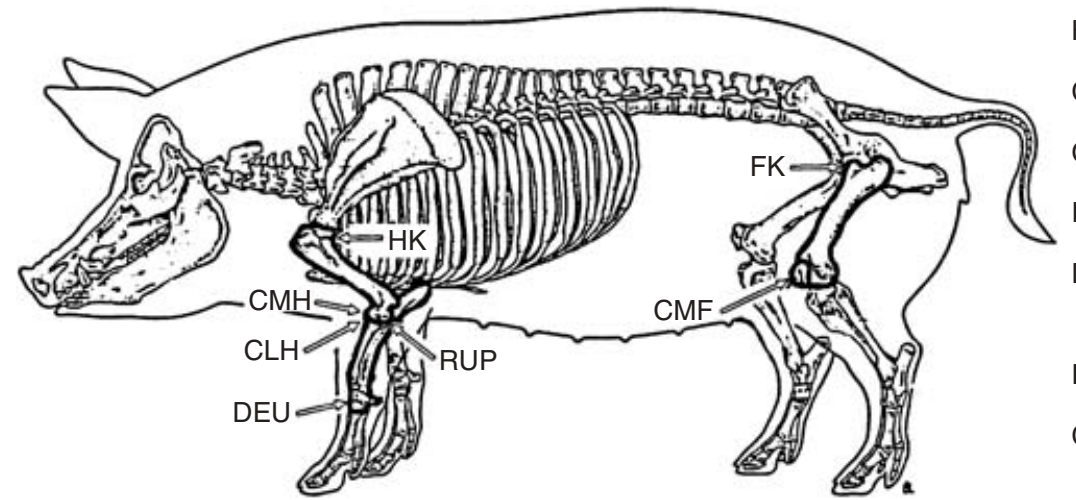

HK: head of humerus
CLH: condylus lateralis humeri
CMH: condylus medialis humeri
RUP: radius and ulna proximal
DEU: distal epiphyseal cartilage
of ulna
FK: head femur
CMF: condylus medialis femoris

Figure 1 Examinations of osteochondral lesions at the Swiss test station (Schwörer et al., 1985).

born at several Swiss breeding farms. Secondly, heritabilities of osteochondral lesions and their genetic correlations with some production and several exterior traits will be estimated.

\section{Material and methods}

\section{Station-test}

In Switzerland, approximately 3000 growing pigs are performance tested per year. Purebred animals of the Large White dam line $\left(\mathrm{LW}_{\mathrm{DL}}\right)$, Swiss Landrace $(\mathrm{SLR})$ and Large White Sire line $\left(\mathrm{LW}_{\mathrm{SL}}\right)$ make up more than $80 \%$ of all test animals. Usually, a test group consists of two full-sibs (one female and one male castrate). Animals are housed in 12 barns, each with eight pens and about 10 animals of both sexes per pen. Electronic feed dispensers are used to feed the animals ad libitum. Two different diets are used during the test. At first, each pig obtains approximately $80 \mathrm{~kg}$ of a starter feed (19\% CP, 13.3 MJ digestible energy (DE), $10 \mathrm{~g} / \mathrm{kg}$ lysine, $8 \mathrm{~g} / \mathrm{kg} \mathrm{Ca}, 5 \mathrm{~g} / \mathrm{kg} \mathrm{P}$ ). Afterwards, a finisher feed (15\% $\mathrm{CP}, 12.7 \mathrm{MJ} D E, 9 \mathrm{~g} / \mathrm{kg}$ lysine, $8 \mathrm{~g} / \mathrm{kg} \mathrm{Ca}, 5 \mathrm{~g} / \mathrm{kg}$ P) is used. The test starts at $30 \mathrm{~kg}$ live weight and ends with approximately $103 \mathrm{~kg}$. Every week, 40 to 70 animals are slaughtered in a small abattoir at the test station and the left half of the carcass is dissected.

Average daily gain (ADG) from 30 to $103 \mathrm{~kg}$ describes the growth of animals. Percentage of premium cuts (PPC) specifies the leanness of carcasses. PPC is defined as the weight of ham, loin and shoulder without fat layer proportional to carcass weight. A full description of the Swiss station-test is given in the annual report of SUISAG (2006).

\section{Examination of bones}

Osteochondral lesions were already observed at the Swiss test station in the 1980s and early 1990s (Schwörer et al., 1991). In 2002, more weight was placed on daily gain in the overall breeding goal. SUISAG decided to monitor the occurrence of osteochondral lesions, because unfavourable genetic correlations with daily gain may exist.

Since 2002, osteochondral lesions have been examined at the following bones and joints: head of humerus (HK), condylus medialis humeri $(\mathrm{CMH})$, condylus lateralis humeri $(\mathrm{CLH})$, radius and ulna proximal (RUP), head of femur (FK), distal epiphyseal cartilage of ulna (DEU) and condylus medialis femoris (CMF). Figure 1 shows the corresponding positions at the carcass. At first, a trained person examines the surface and shape of these bones at the joints. Afterwards each bone is sawed with a band saw and the state and shape of the cartilage and the DEU is examined at the cutting surface. Scores from 1 to 4 are used to record the extent of the osteochondral lesion. A score of 1 denotes 'no visible osteochondral lesion'. Scores 2 to 4 denote 'mildly to severely affected', respectively. Osteochondral lesions at the DEU and CMF are scored from 1 to 6 , because these lesions seemed to be more variable. More details concerning the Swiss examination of osteochondral lesions are given by Schwörer et al. (1985).

\section{Linear description of exterior}

A linear description system (LD) has been used to evaluate exterior characteristics of Swiss gilts and boars (on-farm test) and all station-tested pigs since 2000. Five traits are used to describe the rear and fore extremities: $\mathrm{X}-\mathrm{O}$ posture at rear legs (XORL), side-view angle of rear legs (SVARL), angle of pasterns at rear legs (APRL), size of the inner claw in comparison to the outer claw at rear legs (SICRL) and side-view angle of fore legs (SVAFL). These five traits are scored from 1 to 7 with score 4 as the optimal phenotype and scores 3 to 1 and 5 to 7 as more and more extreme and therefore negative phenotypes. Scores from 4 to 7 are used to describe the regularity at the loin (LOIN). Score 4 denotes 'regular' and scores 5 to 7 denote that the animals are increasingly narrow at the loin in comparison to the whole body. Finally, scores from 4 to 7 are used to evaluate the locomotion (LOC) of the animal. Score 4 denotes 'regular locomotion' and scores 5 to 7 denote a more and more lurching or stiff locomotion. Figure 2 shows a scheme of the linear description system. Tarrés et al. (2006) recently showed that gilts with an optimum exterior - i.e. only scores of 4 at the linear description - stayed longer in the farms compared with gilts with a suboptimal exterior.

The present study includes exterior examinations of station-tested animals, which were performed approximately 


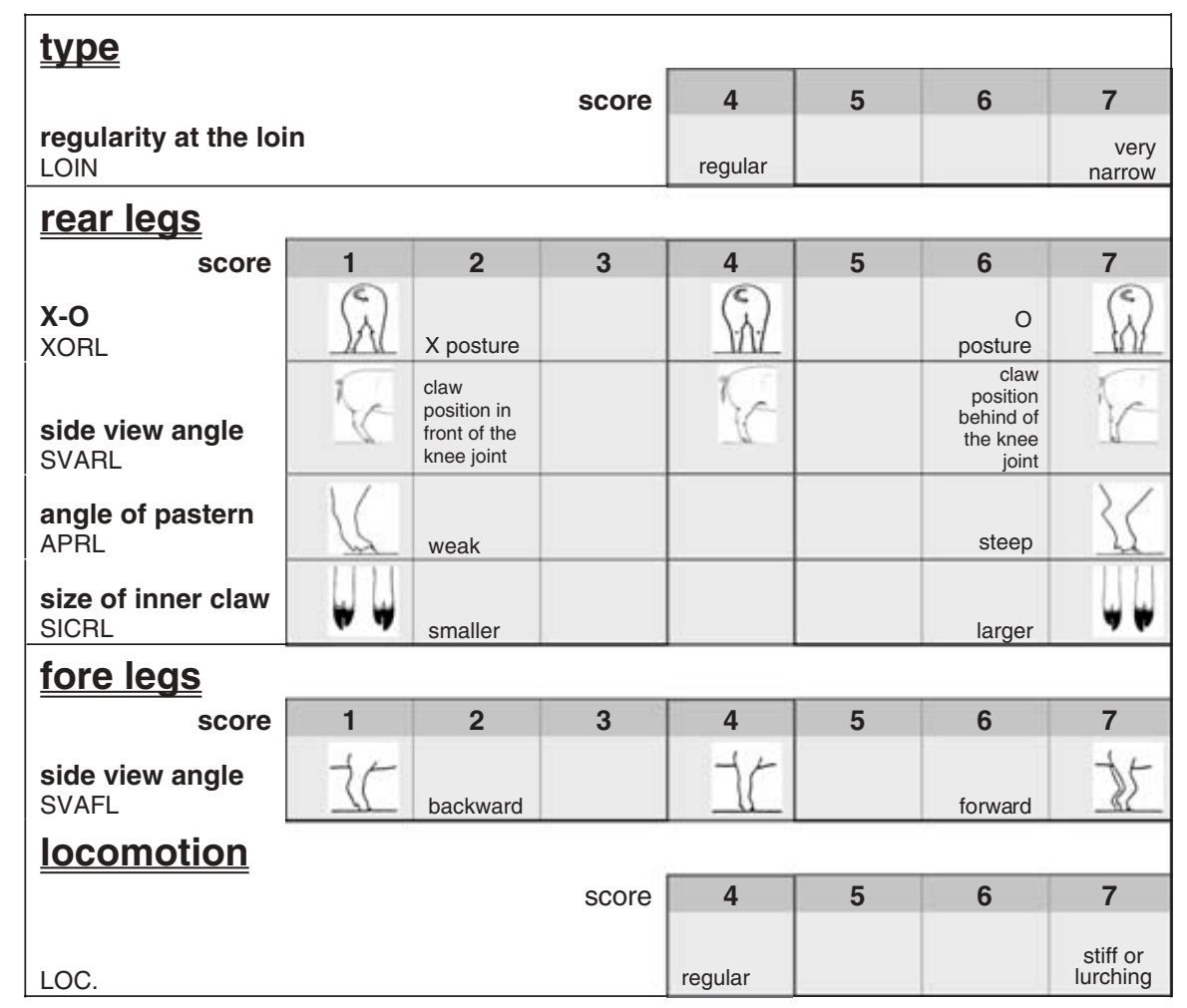

Figure 2 Scheme of the Swiss linear description system (without teat description) (some drawings from Van Steenbergen, 1990).

4 weeks to 1 week before slaughtering. Seven trained persons described the animals during the evaluation period. The length of the carcass $(\mathrm{CL})$ of every animal was measured from the pubis bone to the cervical vertebra after slaughtering. A detailed report of the applied linear description system and the genetic evaluation of exterior traits in Switzerland is given by Hofer (2004).

\section{Data}

This study includes 9511 performance-tested animals of the purebred lines $L W_{D L}, S L R$ and $L W_{S L}$ that were slaughtered between January 2002 and December 2005 (Table 1). Table 2 presents the average fattening and carcass performance of the station-tested animals. The test animals are progeny of 1051 sires and 19988 animals are included in the pedigree file.

About $27 \%$ of all slaughtered animals were examined for osteochondral lesions ( $n=2622$; Table 3). The number of observations was slightly reduced at RUP and DEU, because these bones were used for another project. Data from linear description were available for nearly all animals. Approximately 50 test animals had no or incomplete exterior data due to different reasons (e.g. clinical lameness at description day, etc.).

\section{Statistical analysis}

Genetic parameters were estimated with univariate and multivariate linear mixed animal models using VCE5 (Kovač et al., 2002). Due to the categorical characteristic and the
Table 1 Distribution of station-tested pigs

\begin{tabular}{lrrr}
\hline \hline Breed $^{+}$ & Female & Castrate & Total \\
\hline $\mathrm{LW}_{\mathrm{DL}}$ & 2862 & 3339 & 6201 \\
$\mathrm{SLR}$ & 830 & 934 & 1764 \\
$\mathrm{LW}_{\mathrm{SL}}$ & 852 & 694 & 1546 \\
Total & 4544 & 4967 & 9511 \\
\hline \hline
\end{tabular}

${ }^{+} \mathrm{LW}_{\mathrm{DL}}=$ Large White dam line; SLR $=$ Swiss Landrace; $\mathrm{LW}_{\mathrm{SL}}=$ Large White sire line.

Table 2 Mean and distribution of performance traits $(\mathrm{n}=9511)$

\begin{tabular}{lrrrr}
\hline \hline Trait $^{\dagger}$ & Mean & \multicolumn{1}{c}{ s.d. } & \multicolumn{1}{c}{ Min } & \multicolumn{1}{c}{ Max } \\
\hline LW (kg) & 103.33 & 3.51 & 85.50 & 118.60 \\
ADG (g/day) & 865.38 & 94.10 & 544.60 & 1218.00 \\
FCR (kg/kg) & 2.58 & 0.21 & 1.99 & 3.58 \\
Fl (kg/day) & 2.23 & 0.24 & 1.45 & 3.21 \\
CL (cm) & 96.95 & 2.82 & 85.00 & 110.00 \\
PPC (\%) & 57.66 & 2.54 & 46.98 & 65.90 \\
\hline
\end{tabular}

${ }^{+} \mathrm{LW}=$ live weight at slaughtering; $\mathrm{ADG}=$ average daily gain $(30$ to $103 \mathrm{~kg}) ;$ $\mathrm{FCR}=$ feed conversion ratio; $\mathrm{FI}=$ average daily feed intake; $\mathrm{CL}=$ length of carcass; PPC = percentage of premium cuts.

very skewed distribution, HK, CLH, RUP and FK were excluded from the final statistical analyse. Preliminary univariate estimations showed nearly no genetic variance for these four traits. CMH, DEU and CMF exhibited a prevalence of more than $10 \%$ and remained in the 
statistical analyses with linear models. The heritabilities on the underlying liability scale might be underestimated according to the formula of Robertson and Lerner (1949) due to the use of linear models, especially for $\mathrm{CMH}$. But according to Gianola (1984) the genetic correlations with other continuously distributed traits are almost not affected. Estimations of heritabilities and genetic correlations of the 13 traits were performed in 14 separate runs. It was not possible to run more than seven traits simultaneously. The results of all runs were averaged. Slightly different linear mixed models were used for different traits.

ADG:

$$
\begin{aligned}
y_{\text {himnop }}= & \mu+\text { BREED }_{h}+\text { BARN_PER }_{i}+\text { SEX }_{m} \\
& + \text { farm }_{-} y_{n}+\text { litter }_{o}+\text { animal }_{p}+e_{\text {himnop }}
\end{aligned}
$$

$\mathrm{PPC}, \mathrm{CL}:$

$$
\begin{aligned}
y_{\text {hjmnop }}= & \mu+\mathrm{BREED}_{h}+\mathrm{SL}_{-} \mathrm{DAY}_{j}+\mathrm{SEX}_{m}+b_{m} \mathrm{LW} \\
& + \text { farm }_{-} \mathrm{y}_{n}+\text { litter }_{o}+\text { animal }_{p}+\mathbf{e}_{\text {hjmnop }}
\end{aligned}
$$

XORL, SVARL, APRL, SICRL, SVAFL, LOIN, LOC:

$$
\begin{aligned}
y_{\text {hilmnop }}= & \mu+\mathrm{BREED}_{h}+\mathrm{BARN}_{-} \mathrm{PER}_{i}+\mathrm{LD}_{-} \mathrm{PE}_{l}+\mathrm{SEX}_{m} \\
& + \text { farm }_{-} \mathrm{y}_{n}+\text { litter }_{o}+\text { animal }_{p}+\mathrm{e}_{\text {hilmnop }}
\end{aligned}
$$

CMH, DEU, CMF:

$$
\begin{aligned}
y_{h k m n o p}= & \mu+\text { BREED }_{h}+\text { SL_PER }_{k}+\text { SEX }_{m}+\mathrm{b}_{m} \mathrm{LW} \\
& + \text { farm }_{-} \mathrm{y}_{n}+\text { litter }_{o}+\text { animal }_{p}+e_{h k m n o p}
\end{aligned}
$$

with:

$y$

$\mu \quad$ overall mean

BREED $_{h}$ fixed effect of breed $\left(h=\mathrm{LW}_{\mathrm{DL}}, \mathrm{SLR}, \mathrm{LW}_{\mathrm{SL}}\right)$

BARN_PER ${ }_{i}$ fixed effect of barn $\times$ period combination $(i=1,2, \ldots, 149)$

SL_DAY ${ }_{j}$ the fixed effect of slaughter day $(j=1$, $2, \ldots, 213)$

SL_PER $R_{k}$ fixed effect of slaughter period $(k=1,2$, $\ldots, 8)$

LD_PE, fixed effect of the person performing the $\operatorname{LD}(I=1,2, \ldots, 7)$

SEX ${ }_{m} \quad$ fixed effect of sex ( $m=$ female, castrate)

$b_{m} \mathrm{LW} \quad$ partial linear regression on live weight within sex

farm_ $y_{n} \quad$ random effect of farm of origin $\times$ year

\begin{tabular}{|c|c|c|c|c|c|c|c|}
\hline Score & HK & $\mathrm{CMH}$ & $\mathrm{CLH}$ & RUP & DEU & FK & $\mathrm{CMF}$ \\
\hline \multicolumn{8}{|c|}{ Large White dam line } \\
\hline 1 & 1725 & 1554 & 1722 & 1600 & 235 & 1744 & 1266 \\
\hline 2 & 16 & 156 & 24 & 113 & 677 & 3 & 460 \\
\hline 3 & 7 & 38 & 2 & 1 & 477 & 1 & 20 \\
\hline 4 & 0 & 0 & 0 & 0 & 253 & 0 & 2 \\
\hline 5 & & & & & 72 & & 0 \\
\hline 6 & & & & & 0 & & 0 \\
\hline Total & 1748 & 1748 & 1748 & 1714 & 1714 & 1748 & 1748 \\
\hline \multicolumn{8}{|c|}{ Swiss Landrace } \\
\hline 1 & 408 & 378 & 399 & 391 & 58 & 411 & 240 \\
\hline 2 & 4 & 29 & 12 & 12 & 157 & 1 & 157 \\
\hline 3 & 0 & 5 & 1 & 0 & 117 & 0 & 14 \\
\hline 4 & 0 & 0 & 0 & 0 & 50 & 0 & 1 \\
\hline 5 & & & & & 19 & & 0 \\
\hline 6 & & & & & 2 & & 0 \\
\hline Total & 412 & 412 & 412 & 403 & 403 & 412 & 412 \\
\hline \multicolumn{8}{|c|}{ Large White sire line } \\
\hline 1 & 456 & 407 & 456 & 410 & 42 & 462 & 366 \\
\hline 2 & 5 & 46 & 3 & 36 & 157 & 0 & 92 \\
\hline 3 & 1 & 9 & 3 & 0 & 130 & 0 & 3 \\
\hline 4 & 0 & 0 & 0 & 0 & 87 & 0 & 1 \\
\hline 5 & & & & & 31 & & 0 \\
\hline 6 & & & & & 0 & & 0 \\
\hline Total & 462 & 462 & 462 & 446 & 447 & 462 & 462 \\
\hline
\end{tabular}
$(n=1,2, \ldots, 249)$

litter $_{o} \quad$ random effect of the litter $(o=1,2, \ldots$, 4763)

animal $_{p} \quad$ random effect of the animal $(p=1,2, \ldots$, 9511)

e
Table 3 Distribution of osteochondral lesions within breeds ${ }^{\dagger}$

${ }^{\dagger}$ For abbreviations see Figure 1.

Table 4 Significance of fixed effects ${ }^{\dagger}$

\begin{tabular}{lcccc}
\hline \hline & BREED & SEX & SL_PER & LW \\
\hline CMH & n.s. & $* * *$ & n.s. & n.s. \\
DEU & $* * *$ & n.s. & $* * *$ & $* * *$ \\
CMF & $* * *$ & $* * *$ & $* * *$ & n.s. \\
\hline \hline
\end{tabular}

${ }^{\dagger}$ For abbreviations see Figure 1 and the text. ${ }^{* *} P \leqslant 0.001$.

All test animals that were fattened in the same barn and period were used as a contemporary group for ADG and exterior traits. Eight slaughter periods (6 months) were used as a contemporary group for osteochondral lesions traits, because only approximately 10 to 15 pigs were examined for $\mathrm{OC}$ lesions at each week after slaughtering. The test animals were born at 78 farms within 4 years and belong to 4763 different litters. ADG values were pre-corrected to a constant live weight at slaughtering $(103 \mathrm{~kg})$. Therefore, no regression on live weight was included in the model concerning this trait. No correction for live weight was possible for exterior traits, because pigs were not weighed at the description day.

The statistical software S-PLUS (S-PLUS, 1999) was used to test the significance of fixed effects for osteochondral lesions (Table 4). 
Osteochondral lesions: heritabilities and genetic correlations

\section{Results and discussion}

The occurrence of osteochondral lesions varied at different positions of the carcass (Table 3). Very few animals showed osteochondral lesions at HK, CLH and FK. Only approximately $6 \%$ of all pigs exhibited mildly osteochondral lesions at RUP. Substantial phenotypic variation was observed at $\mathrm{CMH}, \mathrm{CMF}$ and especially at DEU.

The distribution of osteochondral lesions in the present study is in good agreement with Kadarmideen et al. (2004). Those authors used a sub-data set of this study that included only test animals slaughtered in 2002 and 2003. Jørgensen et al. (1995) observed a higher prevalence and variation of subchondral lesions at the medial humeral and femoral condyles in Danish Landrace boars. The prevalence at the lateral humeral condyles was similar to the present study and osteochondral lesions at the distal ulna growth plate showed the most phenotypic variation also. The differences might be caused by different definitions of osteochondral lesion scores, different sexes of the animals and differences between the Swiss and Danish environments and populations. Jørgensen and Andersen (2000) X-rayed Danish Yorkshire and Landrace boars. They observed a slightly higher prevalence of $\mathrm{OC}$ at the humeral condyles and an explicitly higher prevalence at the femoral condyles. Concerning the distal ulna growth line OC scores varied conspicuously in Danish Landrace boars. But $67 \%$ of the Yorkshire boars showed no $\mathrm{OC}$ at this growth plate. So, variation was reduced in the Yorkshire breed.

Differences between breeds were moderate and inconsistent at different positions of the carcass in the present study (Table 3). SLR showed proportionally more osteochondral lesions at CMF but slightly less at RUP compared with Large White dam and sire line. In contrast, Jørgensen and Andersen (2000) reported that Danish Landrace boars were significantly more severely affected than Yorkshire boars regarding $O C$ in all localities except of the anconeal process. Differences between Swiss and Danish populations might be a major reason for this disagreement.

Jørgensen (1995) found no significant differences between sexes concerning $\mathrm{OC}$, which is in good agreement with DEU in the present study (Table 4). Otherwise, castrates were significantly more affected at $\mathrm{CMH}$ and $\mathrm{CMF}$ than females in our study.

Conspicuous phenotypic variation was observed in all linearly described exterior characteristics (Table 5). The scores of XORL showed almost a Gaussian distribution with an average of 3.46. Because 4.0 is the desired average for $X O R L$, it is necessary to reduce the $X$ posture of the rear legs in the Swiss population. Approximately $77 \%$ of all animals exhibited an optimal SVARL. But it is still necessary to reduce the proportion of animals with a 'standing under position' (score 3). On average, the population is very close to the optimum score of 4 concerning the angle of pasterns but a lot of animals showed slightly too weak (score 3 ) or slightly too steep (score 5) pasterns. Most of the animals had a smaller inner claw compared with the outside claw.
Table 5 Distribution of the scores of linear description ${ }^{\dagger}$

\begin{tabular}{|c|c|c|c|c|c|c|c|}
\hline Score & XORL & SVARL & APRL & SCIRL & SVAFL & LOIN & LOC \\
\hline 1 & 6 & 2 & 31 & 265 & 27 & & \\
\hline 2 & 389 & 106 & 350 & 2170 & 159 & & \\
\hline 3 & 4704 & 1799 & 1668 & 5989 & 647 & & \\
\hline 4 & 4003 & 7301 & 5795 & 1027 & 6571 & 2655 & 5647 \\
\hline 5 & 328 & 253 & 1429 & 11 & 1906 & 5721 & 3470 \\
\hline 6 & 30 & 0 & 187 & 0 & 147 & 1079 & 332 \\
\hline 7 & 1 & 0 & 1 & 0 & 4 & 7 & 11 \\
\hline Total & 9461 & 9461 & 9461 & 9462 & 9461 & 9462 & 9460 \\
\hline Mean & 3.46 & 3.81 & 3.93 & 2.83 & 4.12 & 4.83 & 4.44 \\
\hline
\end{tabular}

${ }^{\dagger}$ For abbreviations see Figure 2 .

Table 6 Variance components and heritabilities $\left(\mathrm{h}^{2}\right)$ of osteochondral lesions at different positions of the carcass (univariate estimation) ${ }^{+}$

\begin{tabular}{lcccccccc}
\hline \hline & \multicolumn{7}{c}{ Variance components } \\
\cline { 2 - 8 } & Phenotypic & Farm_y & Litter & Genetic & Error & $c^{2}$ & $h^{2}$ & s.e. \\
\hline CMH & 0.1514 & 0.0000 & 0.0102 & 0.0242 & 0.1170 & 0.07 & 0.16 & 0.04 \\
DEU & 0.9563 & 0.0120 & 0.0119 & 0.1721 & 0.7602 & 0.01 & 0.18 & 0.03 \\
CMF & 0.2371 & 0.0070 & 0.0000 & 0.0418 & 0.1883 & 0.00 & 0.18 & 0.03 \\
\hline
\end{tabular}

${ }^{+} c^{2}=$ ratio of litter variance, s.e. $=$ standard error of $h^{2}$ and for other abbreviations see Figure 1.

Approximately $70 \%$ of all animals showed an optimal angle of the fore legs and the average score is close to the optimum. Nearly $60 \%$ of all pigs showed a fully regular locomotion and approximately $4 \%$ exhibited conspicuous problems (score 6 or 7) concerning locomotion.

Serenius et al. (2001) analysed exterior data of Finnish progeny and performance tests. Approximately 50\% of Finnish Landrace and Large White pigs exhibited small inner claws. Jørgensen (2000) examined 117 Danish crossbred and Yorkshire gilts at 6 months of age for leg weakness symptoms. A high proportion of Danish gilts showed uneven claws especially in crossbred sows. Thus, smaller inner claws seem to be common in different pig populations and pig breeding programmes should aim at equalising the size of both claws in the future.

Approximately 55\% of the 117 Danish gilts (Jørgensen, 2000) exhibited a posture of rear legs called 'turned out', which is synonym to the Swiss ' $X$ posture' and in prevalence very close to our results. About $15 \%$ of the Danish gilts showed too weak pasterns and approximately 20\% too steep pasterns, which is in good agreement to our findings. In contrast, Jørgensen and Andersen (2000) observed only approximately $5 \%$ weak pasterns but about $80 \%$ too steep pasterns in Danish Landrace and Yorkshire boars. Most of the Danish gilts showed a normal locomotion (Jørgensen, 2000). But approximately $25 \%$ exhibited a more or less stiff gait at the rear legs. In contrast, most of the Danish boars showed a stiff locomotion (Jørgensen and Andersen, 2000). The Danish results suggest that the occurrence of leg weakness symptoms is different between sows and boars 
Luther, Schwörer and Hofer

Table 7 Heritabilities (diagonal, bold), phenotypic correlations (above diagonal) and genetic correlations (below diagonal) of multivariate analyses ${ }^{t}$

\begin{tabular}{|c|c|c|c|c|c|c|c|c|c|c|c|c|c|}
\hline & ADG & PPC & XORL & SVARL & APRL & SICRL & SVAFL & LOC & $C L$ & LOIN & $\mathrm{CMH}$ & DEU & CMF \\
\hline ADG & 0.27 & -0.25 & 0.04 & 0.01 & 0.00 & -0.03 & -0.01 & 0.04 & -0.12 & 0.00 & -0.01 & 0.00 & 0.09 \\
\hline PPC & -0.07 & 0.62 & -0.03 & 0.00 & 0.07 & -0.01 & 0.07 & 0.02 & 0.17 & 0.24 & -0.02 & 0.03 & -0.03 \\
\hline XORL & 0.08 & 0.02 & 0.13 & -0.02 & -0.19 & -0.01 & -0.10 & -0.12 & -0.12 & -0.02 & -0.02 & 0.02 & 0.01 \\
\hline SVARL & -0.09 & -0.06 & -0.05 & 0.10 & 0.14 & 0.07 & -0.01 & -0.20 & -0.03 & -0.12 & -0.03 & 0.02 & -0.06 \\
\hline APRL & -0.12 & 0.09 & -0.45 & 0.40 & 0.26 & 0.02 & 0.14 & 0.02 & 0.02 & 0.01 & 0.02 & -0.04 & -0.01 \\
\hline SICRL & 0.00 & -0.08 & -0.17 & 0.18 & 0.08 & 0.15 & -0.04 & -0.11 & -0.06 & -0.05 & -0.03 & -0.01 & -0.08 \\
\hline SVAFL & -0.07 & 0.13 & -0.45 & 0.07 & 0.40 & -0.04 & 0.14 & 0.11 & 0.13 & 0.02 & -0.03 & 0.02 & 0.02 \\
\hline LOC & 0.30 & -0.05 & -0.12 & -0.57 & 0.03 & -0.29 & 0.20 & 0.14 & 0.04 & 0.13 & 0.01 & -0.01 & 0.03 \\
\hline $\mathrm{CL}$ & -0.10 & 0.17 & -0.25 & -0.17 & -0.09 & -0.06 & 0.28 & -0.06 & 0.61 & 0.01 & -0.03 & -0.03 & 0.02 \\
\hline LOIN & 0.16 & 0.50 & 0.08 & -0.28 & 0.12 & -0.14 & 0.00 & 0.41 & 0.03 & 0.20 & 0.00 & 0.00 & 0.00 \\
\hline $\mathrm{CMH}$ & -0.11 & 0.06 & -0.17 & -0.27 & -0.04 & -0.16 & -0.01 & 0.16 & -0.07 & -0.20 & 0.17 & 0.01 & 0.06 \\
\hline DEU & 0.01 & 0.06 & 0.01 & $\overline{-0.15}$ & -0.11 & $\overline{-0.20}$ & -0.09 & $\overline{0.54}$ & -0.07 & 0.18 & 0.13 & 0.17 & 0.01 \\
\hline CMF & 0.21 & 0.11 & 0.11 & $\overline{-0.14}$ & -0.12 & -0.25 & -0.03 & $\overline{0.27}$ & 0.12 & $\overline{0.20}$ & -0.14 & -0.10 & 0.17 \\
\hline
\end{tabular}

${ }^{\dagger}$ For abbreviations see Figures 1 and 2 and Table 2. Underlined values indicate notable genetic correlation is favourable $\left(r_{g} \geqslant \pm 0.15\right)$. Italic values indicate notable genetic correlation is unfavourable $\left(r_{g} \geqslant \pm 0.15\right)$.

especially for pasterns and locomotion. In the present study we did not find differences between females and castrates concerning exterior traits.

\section{Heritabilities and correlations}

At first, univariate analyses were performed to estimate the variance components of osteochondral lesion at $\mathrm{CMH}$, DEU and CMF (Table 6). The additive genetic effect explains a noticeable proportion of the total phenotypic variance of osteochondral lesions. Hence, heritabilites for these traits ranged from $h^{2}=0.16$ to 0.18 . The corresponding standard errors were low.

The random effect farm of origin $\times$ year combination explains nearly no variance. This indicates that the farm of origin does not influence the occurrence of osteochondral lesions at the end of the station test significantly. Concerning osteochondral lesions at $\mathrm{CMH}$, the litter effect explains a minor proportion of the total variance. This means that pigs of the same litter show more frequently $O C$ lesions than one would expect due to the identical parentage. Environmental effects, e.g. low milk production of the nursing dam, could be a potential explanation for this observation. But on the other hand no noticeable litter effect was observed for DEU and CMF.

Kadarmideen et al. (2004) estimated very low heritabilities for osteochondral lesions using linear mixed sire models except for RUP and CMF. But the authors used threshold models too. Heritabilities obtained from these threshold models ranged between $h^{2}=0.00$ (FK) and $h^{2}=0.42(\mathrm{CMH})$. Transformed to the 'observed scale', these heritabilities are in good agreement with the values of the present study except for DEU, which was not significantly different from zero in the study of Kadarmideen et al. (2004).

Jørgensen and Andersen (2000) estimated heritabilities of $O C$ at six different positions of the carcass. The values ranged from $h^{2}=0.08$ to 0.39 and varied sometimes between Danish Yorkshire and Landrace breeds at the same position of the carcass. On average, the heritabilities in Danish populations were higher than in the present study. Differences between Danish and Swiss populations might be a potential reason. Obviously, there were distinctions between Danish breeds. We did not estimate genetic parameters of the three Swiss breeds separately, because less than 500 SLR and SLW $S$ test animals had OC data, respectively. Moreover, phenotypic variation of $O C$ was more pronounced in Danish populations compared with the present study. Jørgensen and Andersen (2000) examined both sides of the animal radiologically for osteochondral lesions and analysed the average score statistically. The different methods of examination might have affected the incidence and variation of $\mathrm{OC}$ and could be another cause of different heritabilities.

Table 7 presents the results of the multivariate estimation of genetic parameters. Phenotypic correlations of osteochondral lesions to exterior and production traits were close to zero. Heritabilities of osteochondral lesions changed slightly due to the multivariate estimation in comparison to the univariate analyses. Linearly described exterior traits showed low heritabilities $(0.10$ to 0.20$)$. But all values differed significantly from zero. CL and the PPC exhibited the highest heritabilities of all traits $(0.61$ and 0.62 , respectively). Serenius et al. (2001) estimated lower heritabilities for leg weakness symptoms in comparison to our findings. The present results are in good agreement with Jørgensen and Andersen (2000).

Genetic correlations between osteochondral lesions at $\mathrm{CMH}, \mathrm{DEU}$ and CMF were low $\left(r_{g}=-0.14\right.$ to 0.13$)$. This indicates that the occurrence of osteochondral lesions at the three positions does not seem to be controlled by identical genes and should be considered as different traits. This conclusion agrees with Jørgensen and Andersen (2000) and Kadarmideen et al. (2004).

The genetic correlations of osteochondral lesions to ADG and PPC were very low. Only the unfavourable genetic 
correlation between osteochondral lesions at CMF and ADG exceeded $r_{g}= \pm 0.15$ in the present study. Thus, genetic selection that favours leaner and faster growing pigs does not seem to increase the genetic predisposition to exhibit osteochondral lesions considerably in Swiss breeds. Our results are in agreement with Lundeheim and Rydhmer (1990), Jørgensen and Andersen (2000) and Kadarmideen et al. (2004). Those authors estimated few unfavourable genetic correlations with moderate magnitude between $O C$ and production traits. In the same way, Jørgensen (1995) did not find different prevalences of $O C$ between pigs fed restricted $v$. ad libitum although the pigs fed ad libitum grew faster. In contrast, Busch et al. (2006) reported that a high ADG was associated with an increased risk to exhibit $O C$.

Genetic correlations of osteochondral lesions at $\mathrm{CMH}$, DEU and CMF to exterior traits showed low to medium values. Nearly all correlations that exceed $r_{g}= \pm 0.15$ were favourable concerning the actual Swiss breeding goal. Especially the occurrence of osteochondral lesions at DEU and the regularity of locomotion seem to be genetically linked $\left(r_{g}=0.54\right)$. Only the association between regularity at the loin and $\mathrm{CMH}$ was genetically unfavourable and exceeded $r_{g}= \pm 0.15$. Therefore, genetically favouring animals with regular locomotion and optimal exterior would reduce the occurrence of osteochondral lesions in the long-term especially at DEU.

In general, our results agree with results by Jørgensen (2000) and Jørgensen et al. (1995). Those authors also found slight phenotypic associations between several leg weakness symptoms and pathological changes of bones and joints. Jørgensen and Andersen (2000) estimated some moderate genetic correlations between leg weakness symptoms and $\mathrm{OC}$ at the femoral and humeral condyles too.

\section{Conclusion and implications}

At HK, CLH, RUP and CMF even mildly osteochondral lesions are rare in Swiss breeds. More than $10 \%$ of the pigs exhibited mostly mildly osteochondral lesion at the $\mathrm{CMH}$, DEU and CMF, respectively. Thus, based on the stationtested pigs osteochondral lesions do not seem to be a severe problem in Swiss breeds at the moment. The occurrence of osteochondral lesions at $\mathrm{CMH}$, DEU and CMF is heritable $\left(h^{2}=0.16\right.$ to 0.18$)$. Therefore, it is possible to reduce the prevalence of osteochondral lesions by selection in principle.

Direct selection would require examination of all tested pigs for OC lesions, which is too costly. An indirect selection based on exterior traits is difficult due to low heritabilities of $O C$ and exterior traits and low relative weight of exterior in the overall breeding goal. But the low genetic correlations between the most important production traits (ADG and PPC) and osteochondral lesions as well as the favourable genetic correlations with Swiss exterior traits suggest that the prevalence of $O C$ will not increase, if gilts and boars are selected according to the Swiss breeding goal.
Nevertheless, SUISAG will continue the examinations of a random sample of station-tested pigs after slaughtering to observe the further development of osteochondral lesions in the Swiss breeds directly.

\section{Acknowledgments}

Authors thank both reviewers for their helpful comments in preparing this paper.

\section{References}

Busch ME, Christensen G, Wachmann H and Olsen P 2006. Osteochondrosis of the elbow joint in finishers - association with growth rate and heritability. Proceedings of the 19th international pig veterinary society congress, Copenhagen, Denmark, vol. 1, p. 110.

Gianola D 1984. Theory and analysis of threshold characters. Journal of Animal Science 54, 1079-1096.

Hofer A 2004. [Consideration of exterior traits in selection.] 6. Schweine Workshop Uelzen 2004 DGFZ-Schriftenreihe 33, 66-76.

Jørgensen B 1995. Effect of different energy and protein levels on leg weakness and osteochondrosis in pigs. Livestock Production Science 41, 171-181.

Jørgensen B 2000. Osteochondrosis/osteoarthrosis and claw disorders in sows, associated with leg weakness. Acta Veterinaria Scandinavica 41, 123-138.

Jørgensen B and Andersen S 2000. Genetic parameters for osteochondrosis in Danish Landrace and Yorkshire boars and correlations with leg weakness and production traits. Animal Science 71, 427-434.

Jørgensen B, Arnbjerg J and Aaslyng M 1995. Pathological and radiological investigations on osteochondrosis in pigs, associated with leg weakness. Journal of Veterinary Medicine, Series A 42, 489-504.

Kadarmideen HN, Schwörer D, llahi H, Malek M and Hofer A 2004. Genetics of osteochondral disease and its relationship with meat quality and quantity, growth and feed conversion traits in pigs. Journal of Animal Science 82, 3118-3127.

Kovač M, Groeneveld E and García-Cortés LA 2002. VCE-5, a package for the estimation of dispersion parameters. Proceedings of the seventh world congress on genetics applied to livestock production, Montpellier, Communication no. 28-06

Lundeheim N 1987. Genetic analysis of osteochondrosis and leg weakness in the Swedish pig progeny testing scheme. Acta Agriculturæ Scandinavica 37, 159-173.

Lundeheim N and Rydhmer L 1990. Genetic analysis of osteochondrosis and leg weakness in the Swedish Landrace pig population. Proceedings of the fourth world congress on genetics applied to livestock production, Edinburgh, vol. XV, pp. 493-496.

Olsson S-E and Reiland S 1978. The nature of osteochondrosis in animals. Summary and conclusions with comparative aspects on osteochondritis dissecans in man. Acta Radiologica (Suppl.) 358, 299-306.

Robertson A and Lerner IM 1949. The heritability of all-or-none traits: liability of poultry. Genetics 34, 395-411.

Schwörer D, Häni HJ and Blum JK 1985. [Leg weakness symptoms and abnormalities of joints in fattening pigs]. Der Kleinviehzüchter 33, 634-644.

Schwörer D, Lorenz D and Rebsamen A 1991. [Impact of healthy limbs in pig breeding.] Der Kleinviehzüchter 39, 781-795.

Serenius T, Sevón-Aimonen M-L and Mäntysaari EA 2001. The genetics of leg weakness in Finnish Large White and Landrace populations. Livestock Production Science 69, 101-111.

S-PLUS 1999. S-PLUS, 2000 user's guide. Seattle, Washington.

SUISAG 2006. [Annual report.] http://www.suisag.ch.

Tarrés J, Bidanel JP, Hofer A and Ducroq V 2006. Analysis of longevity and exterior traits on Large White sows in Switzerland. Journal of Animal Science 84, 2914-2924.

Van Steenbergen EJ 1990. Relevance of exterior appraisal in pig breeding. PhD thesis, Wageningen University, The Netherlands. 